\title{
Risk of Cancer-Specific Death for Patients Diagnosed With Neuroendocrine Tumors: A Population-Based Analysis
}

\author{
Julie Hallet, MD, MSc 1,2,3,4; Calvin Law, MD, MPH'1,2,4; Simron Singh, MD, MPH 1,2,3,4; Alyson Mahar, $\mathrm{PhD}^{5}$; \\ Sten Myrehaug, MD ${ }^{1,2,4}$; Victoria Zuk, $\mathrm{MSc}^{4}$; Haoyu Zhao, $\mathrm{MPH}^{3}$; Wing Chan, $\mathrm{MPH}^{3}$; \\ Angela Assal, MD, MSc ${ }^{1,2}$; and Natalie Coburn, MD, $\mathrm{MPH}^{1,2,3,4}$
}

\begin{abstract}
Background: Although patients with neuroendocrine tumors (NETs) are known to have prolonged overall survival, the contribution of cancer-specific and noncancer deaths is undefined. This study examined cancer-specific and noncancer death after NET diagnosis. Methods: We conducted a population-based retrospective cohort study of adult patients with NETs from 2001 through 2015. Using competing risks methods, we estimated the cumulative incidence of cancer-specific and noncancer death and stratified by primary NET site and metastatic status. Subdistribution hazard models examined prognostic factors. Results: Among 8,607 included patients, median follow-up was 42 months (interquartile range, 17-82). Risk of cancerspecific death was higher than that of noncancer death, at $27.3 \%$ (95\% Cl, 26.3\%-28.4\%) and 5.6\% (95\% Cl, 5.1\%-6.1\%), respectively, at 5 years. Cancer-specific deaths largely exceeded noncancer deaths in synchronous and metachronous metastatic NETs. Patterns varied by primary tumor site, with highest risks of cancer-specific death in bronchopulmonary and pancreatic NETs. For nonmetastatic gastric, small intestine, colonic, and rectal NETs, the risk of noncancer death exceeded that of cancer-specific deaths. Advancing age, higher material deprivation, and metastases were independently associated with higher hazards, and female sex and high comorbidity burden with lower hazards of cancer-specific death. Conclusions: Among all NETs, the risk of dying of cancer was higher than that of dying of other causes. Heterogeneity exists by primary NET site. Some patients with nonmetastatic NETs are more likely to die of noncancer causes than of cancer causes. This information is important for counseling, decision-making, and design of future trials. Cancer-specific mortality should be included in outcomes when assessing treatment strategies.
\end{abstract}

J Natl Compr Canc Netw 2021;19(8):935-944 doi: 10.6004/jnccn.2020.7666

${ }^{1}$ Faculty of Medicine, University of Toronto, Toronto, Ontario; ${ }^{2}$ Susan Leslie Clinic for Neuroendocrine Tumors-Odette Cancer Centre, Sunnybrook Health Sciences Centre, Toronto, Ontario; ${ }^{3}$ ICES, Toronto, Ontario; ${ }^{4}$ Cancer Program-Clinical Evaluative Sciences, Sunnybrook Research Institute, Toronto, Ontario; and ${ }^{5}$ Department of Community Health Sciences, University of Manitoba, Winnipeg, Manitoba, Canada.

\section{Background}

With increasing incidence worldwide and prolonged survival in the presence of active cancer because of unique tumor biology, neuroendocrine tumors (NETs) are now more prevalent than pancreatic, esophageal, and gastric cancers combined. ${ }^{1-5}$ There have been more clinical trials, new drug development studies, and epidemiology and healthcare delivery analyses that have improved the knowledge of and therapeutic options for NETs. ${ }^{4-9}$ However, information on the burden of cancer on mortality for patients with NETs remains scarce.

NETs are a heterogeneous malignancy with variable biologic, clinical, and prognostic characteristics. There is an evolving need to adapt treatment plans to their unique biology and chronic behavior, which is generally atypical for malignancies. With prolonged survival and more frequent incidental findings, patients with NETs may not die of their disease. ${ }^{4,5}$ Understanding the cancer and noncancer prognosis of NETs is critical in guiding decisions regarding care, monitoring strategies, aggressiveness of therapy, and patient counseling to enable shared decisionmaking. ${ }^{10}$ Yet, although overall survival, recurrence-free survival, and associated prognostic factors have been described in several studies, few have reported cancerspecific survival..$^{4,5,11-15}$ Existing studies are limited to a single NET primary tumor site, consider a specific treatment modality, and do not address competing risks. ${ }^{11,13-15}$

Thus, we conducted a population-based study of patients diagnosed with NETs to examine cancer and noncancer deaths after diagnosis and identify prognostic factors associated with cause-specific death.

\section{Methods}

Study Design

We conducted a population-based retrospective cohort study using prospectively collected administrative datasets

See JNCCN.org for supplemental online content. 
linked to administrative health databases stored at ICES in Toronto, Canada. The study was approved by Sunnybrook Health Sciences Centre Research Ethics Board, and was conducted and reported following the RECORD statement ${ }^{16}$ and the PROGnosis RESearch Strategy (PROGRESS). ${ }^{10}$

\section{Data Sources}

Datasets used included the Ontario Cancer Registry (OCR), Registered Persons Database (RPDB), Ontario Health Insurance Plan (OHIP), and Ontario Registrar General Death database (ORGD) ${ }^{17-19}$ Detailed information on all the databases used are provided in supplemental eTable 1 (available with this article at JNCCN.org). Datasets were linked using unique encoded identifiers at ICES.

\section{Study Population and Cohort}

Under the Canada Health Act, Ontario's 13.5 million residents benefit from universally accessible and publicly funded healthcare though OHIP. ${ }^{20}$ Adult patients (aged $\geq 18$ years) diagnosed with NETs from January 1,2001 , through December 31, 2015, were identified in the OCR with ICD-O-3 codes using a previously reported strategy (supplemental eTable 2).,21

\section{Outcomes}

Our primary outcome was death after NET diagnosis, classified as cancer-specific death or noncancer death. Time to death was calculated from date of diagnosis to date of death. Cancer-specific death was defined as ICD-9 codes 140 through 239 (topography codes for any cancer death whether from NET or other histology) and noncancer death as other codes in the ORGD. The primary cause of death was defined as the antecedent cause of death when available or the immediate cause of death when antecedent causes were not captured. High agreement in cause of death has been reported between ORGD and clinical follow-up in a prospective cohort of patients with cancer. ${ }^{22}$ Noncancer cause of death was further described using a previously described strategy (supplemental eTable 3). ${ }^{23}$ The category "other cause of death" included stomach and duodenal ulcers; complications of pregnancy, childbirth, and the perinatal period; congenital anomalies; homicide and legal intervention; and other causes of death. Proportion of patients for each cause of death was reported for 2 time periods: $\leq 5$ and $>5$ years from date of NET diagnosis. Participants were observed until date of death, date of last clinical contact, or December 31, 2016, allowing for a minimum of 12 months of follow-up for each patient.

\section{Covariates}

Baseline characteristics were measured at the time of diagnosis. Rural living was determined using the rurality index of Ontario based on the postal code of the patients' primary residence, with index $\geq 40$ representing rural residence. ${ }^{24}$ Material deprivation is a composite index of the inability for individuals or households to afford consumption goods and activities typical in a society at a given point in time..$^{25,26}$ Baseline comorbidity burden was measured using the Johns Hopkins Adjusted Clinical Group system score based on health services use with a 24-month look-back window before the date of NET diagnosis. ${ }^{27,28}$ The 32 aggregated diagnosis groups (ADGs) were summed and dichotomized, with a cutoff of 10 for high comorbidity burden..$^{28,29}$

NETs were subdivided according to primary tumor site into bronchopulmonary, gastroenteric, pancreatic, and others using ICD-O-3 topography codes. Gastroenteric NETs were further subdivided as gastric, small intestinal, colonic, and rectal. Metastatic disease was defined using ICD-9 and ICD-10 codes and divided into synchronous metastases (metastasis code $\leq 6$ months from the date of NET diagnosis) and metachronous metastases (metastasis code $>6$ months after the date of NET diagnosis) (supplemental eTable 4).

\section{Statistical Analysis}

Treating time to death as a time-to-event variable, we estimated the cumulative incidence of death after NET diagnosis using the cumulative incidence function for cancer death, treating noncancer death as a competing risk. ${ }^{30,31}$ We reported estimates for probability of death as percentages with $95 \%$ confidence intervals at 5 and 10 years. Because use of ICD-9 codes to define cancerspecific death relies on topography and not histology, it is possible that cancer-specific deaths would have been related to non-NET cancer. To explore the potential contribution of non-NET cancer-specific death to the results, we conducted a sensitivity analysis that excluded patients with a non-NET cancer diagnosis after NET diagnosis.

To explore the independent association of potential prognostic factors on the probability of noncancer death, we constructed multivariable subdistribution hazard models.32,33 We selected potential prognostic factors a priori based on clinical relevance and literature review, including age, sex, primary tumor site, material deprivation quintile, rural residence, year of diagnosis (dichotomous), and metastatic status. ${ }^{4,5,32}$ We reported the subdistribution hazard ratios (sHRs) with 95\% confidence interval.

We examined missing data for key variables. Data were missing for rural residency in $1.2 \%$ and material deprivation in $1.1 \%$ of the cohort. We performed a complete case analysis whereby patients with missing data were excluded for analyses using these variables. Statistical significance was set at $P \leq .05$. All analyses were conducted using SAS Enterprise Guide 7.1 (SAS Institute Inc.).

\section{Results}

Of 8,707 identified patients with NET diagnosis, 91 were excluded for being aged $<18$ or $>105$ years and 9 for 
having a date of death recorded before the date of NET diagnosis. The final cohort comprised 8,607 patients diagnosed with NETs (Table 1 and supplemental eTable 5). Median follow-up was 42 months (interquartile range [IQR], 17-82 months) and there were 3,121 (36.3\%) death events during follow-up, of which 2,487 were because of cancer. The most common primary tumor site was bronchopulmonary (22.8\%), followed by small intestine (19.3\%) and rectum (14.4\%). A total of $42.2 \%$ of patients had metastases, including $32.0 \%$ synchronous metastases. This varied by primary tumor sites. For rectal and pancreatic NET, $90.8 \%$ and $70.7 \%$ of patients, respectively, did not have metastases. A non-NET cancer was diagnosed after NET diagnosis in 765 patients.

Overall survival for the entire cohort was $67.1 \%$ (95\% CI, $66.0 \%-68.1 \%)$ at 5 years and $55.1 \%(95 \% \mathrm{CI}$, $53.6 \%-56.6 \%)$ at 10 years. The cumulative incidences of cancer-specific deaths along with the competing risk of noncancer death for the entire cohort are presented in Figure 1. The risk of cancer-specific death for all patients was higher than that of noncancer death, with $27.3 \%$ (95\% CI, 26.3\%-28.4\%) and $5.6 \%$ (95\% CI, 5.1\%-6.1\%), respectively, at 5 years, and $34.5 \%$ (95\% CI, 33.2\%-35.8\%) and $10.3 \%$ (95\% CI, $9.4 \%-11.3 \%)$, respectively, at 10 years. In patients with metastatic disease, both synchronous and metachronous, the risk of cancer-specific death largely exceeded that of noncancer death immediately after diagnosis. In patients without metastases, the risk of cancer-specific and noncancer deaths paralleled each other. Cancerspecific death was initially slightly higher than noncancer death with $7.7 \%$ (95\% CI, 7.0\%-8.6\%) and $6.2 \%$ $(95 \%$ CI, $5.4 \%-6.9 \%)$ at 5 years, respectively. Only after 8 years from diagnosis did the risk of noncancer death (11.7\%; 95\% CI, $10.4 \%-13.2 \%$, at 10 years) become slightly higher than that of cancer-specific death (10.2\%; 95\% CI, 9.1\%-11.3\%, at 10 years). Sensitivity analysis excluding patients with non-NET cancer diagnosis after NET diagnosis did not substantially alter the results (supplemental eFigure 1).

Different patterns of cancer and noncancer deaths were observed depending on the primary NET site. When considering all patients, regardless of metastatic status, the risk of cancer-specific death was consistently higher than that of noncancer death; however, the magnitude of the cancer-specific death varied (Figures 2 and 3, and supplemental eFigure 2). The highest risks of cancer-specific death were observed for bronchopulmonary NETs, with $36.4 \%$ $(95 \% \mathrm{CI}, 34.2 \%-38.7 \%)$ at 5 years and $42.7 \%(95 \% \mathrm{CI}$, $0.1 \%-45.3 \%$ ) at 10 years (Figure 3 ). This was followed by pancreatic NETs $(34.8 \%$ [95\% CI, 31.5\%-38.2\%] at 5 years and $48.4 \%$ [95\% CI, $43.5 \%-53.0 \%$ ] at 10 years)

\begin{tabular}{|c|c|}
\hline Characteristic & n (\%) \\
\hline Patients, N & 8,607 \\
\hline \multicolumn{2}{|l|}{ Age at diagnosis, $y$} \\
\hline$<50$ & $1,862(21.6)$ \\
\hline $50-59$ & $2,004(23.3)$ \\
\hline $60-69$ & $2,226(25.9)$ \\
\hline$\geq 70$ & $2,515(29.2)$ \\
\hline \multicolumn{2}{|l|}{ Sex } \\
\hline Female & $4,323(50.2)$ \\
\hline Male & $4,284(49.8)$ \\
\hline \multicolumn{2}{|l|}{ Year of diagnosis } \\
\hline $2001-2008$ & $2,961(34.4)$ \\
\hline 2009-2015 & $5,646(65.6)$ \\
\hline \multicolumn{2}{|l|}{ Location of residence } \\
\hline Missing & $102(1.2)$ \\
\hline Rural & $824(9.6)$ \\
\hline Urban & $7,681(89.2)$ \\
\hline \multicolumn{2}{|l|}{ Material deprivation quintile } \\
\hline Missing & $93(1.1)$ \\
\hline 1st (least deprived) & $1,648(19.1)$ \\
\hline 2nd & $1,704(19.8)$ \\
\hline $3 r d$ & $1,660(19.3)$ \\
\hline 4 th & $1,724(20.0)$ \\
\hline 5th (most deprived) & $1,778(20.7)$ \\
\hline \multicolumn{2}{|l|}{ Comorbidity burden } \\
\hline Low (ADG <10) & $6,210(72.2)$ \\
\hline High (ADG $\geq 10$ ) & $2,397(27.8)$ \\
\hline \multicolumn{2}{|l|}{ Metastatic status } \\
\hline None & $4,978(57.8)$ \\
\hline Synchronous ${ }^{\mathrm{a}}$ & $2,754(32.0)$ \\
\hline Metachronous $^{b}$ & $875(10.2)$ \\
\hline Median duration of follow-up (IQR), mo & $42(17-82)$ \\
\hline Death of any cause during follow-up & $3,121(36.3)$ \\
\hline
\end{tabular}

Abbreviations: $A D G$, aggregated diagnosis group; IQR, interquartile range. aSynchronous: $<6$ months from diagnosis.

bMetachronous: $\geq 6$ months from diagnosis.

(Figure 2) and colonic NETs (21.4\% [95\% CI, 18.9\%-24.0\%] at 5 years and $26.6 \%$ [95\% CI, $23.4 \%-29.9 \%]$ at 10 years) (Figure 4). When stratifying by metastatic status, the risk of cancer-specific death largely exceeded that of noncancer death across all primary NET sites, with most of the increase in cancer-specific death occurring in the first 2 years after diagnosis.

In certain scenarios of nonmetastatic NET, the cumulative incidence of cancer-specific death was lower than that of noncancer death (Figure 4). For nonmetastatic gastric NETs, incidence of noncancer 
A

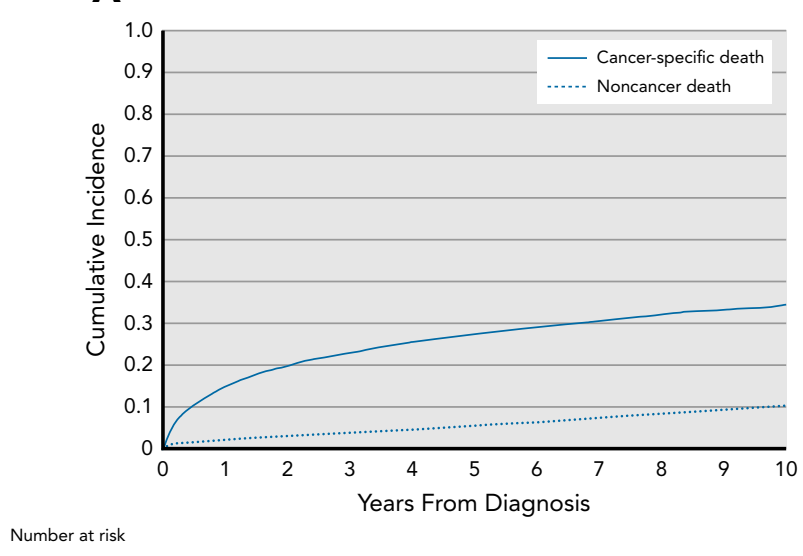

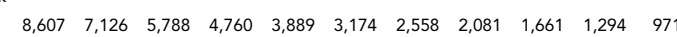

B

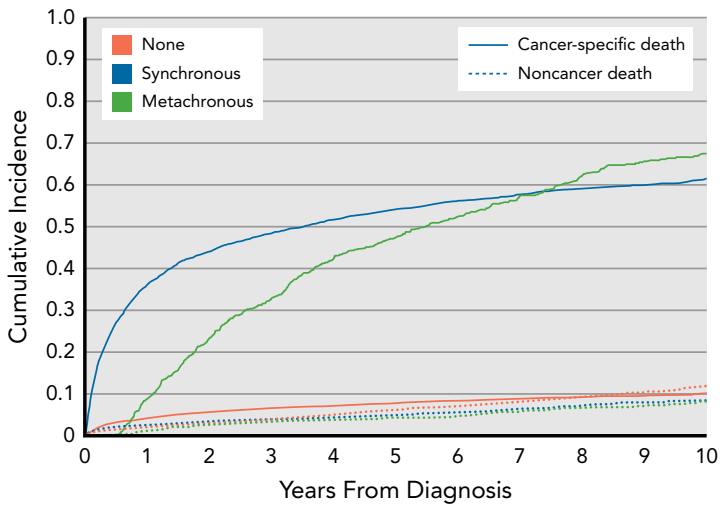

Number at risk

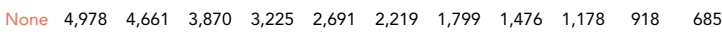
$\begin{array}{lllllllllllll}\text { Synchronous } & 2,754 & 1,679 & 1,296 & 1,025 & 801 & 627 & 501 & 407 & 330 & 262 & 201\end{array}$

$\begin{array}{llllllllllll}\text { Metachronous } & 875 & 788 & 624 & 514 & 400 & 331 & 259 & 200 & 155 & 118 & 87\end{array}$

Figure 1. Cancer-specific death and noncancer death cumulative incidence after neuroendocrine tumor diagnosis for (A) all patients and (B) stratified by metastatic status.

death became higher than cancer-specific death starting at 1 year after diagnosis, with $10.4 \%(95 \% \mathrm{CI}, 7.1 \%-14.4 \%)$ at 5 years and $18.9 \%(95 \% \mathrm{CI}, 13.4 \%-25.2 \%)$ at 10 years versus $5.8 \%(95 \% \mathrm{CI}, 3.5 \%-8.9 \%)$ at 5 years and $9.0 \%(95 \%$ CI, $5.1 \%-14.3 \%$ ) at 10 years, respectively (Figure 4 ). The same was observed for nonmetastatic small intestine NETs from the time of diagnosis, with $13.0 \%$ (95\% CI, $10.2 \%-16.0 \%)$ at 5 years and $22.4 \%$ (95\% CI, $17.7 \%-27.4 \%)$ at 10 years for noncancer death versus $4.7 \%$ (95\% CI, $3.1 \%-6.7 \%)$ at 5 years and $8.6 \%(95 \% \mathrm{CI}, 5.7 \%-12.3 \%)$ at 10 years for cancer-specific death, as well as for colonic NETs starting at 3 years after diagnosis, with noncancer death of $6.4 \%(95 \% \mathrm{CI}, 4.5 \%-8.8 \%)$ at 5 years and $11.4 \%$

A

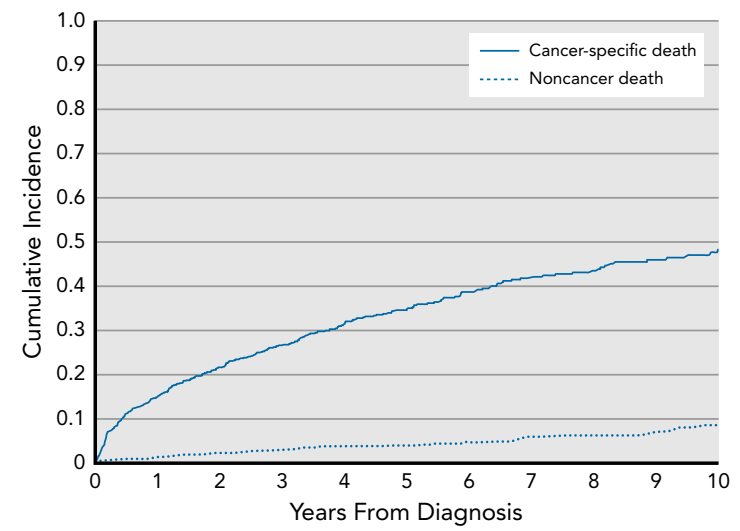

Number at risk

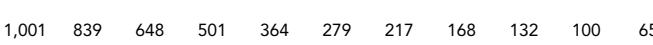

(95\% CI, $7.9 \%-15.6 \%)$ at 10 years, and cancer-specific death of $4.1 \%(95 \% \mathrm{CI}, 2.7 \%-5.9 \%)$ at 5 years and $5.9 \%$ (95\% CI, $3.8 \%-8.6 \%)$ at 10 years, and finally rectal NETs starting at 2 years after diagnosis, with noncancer death of $2.7 \%$ (95\% CI, $1.8 \%-3.9 \%$ ) at 5 years and $6.6 \%$ (95\% CI, $4.7 \%-9.0 \%)$ at 10 years, and cancer-specific death of $7.4 \%$ (95\% CI, $5.9 \%-8.9 \%)$ at 5 years and $9.3 \%$ (95\% CI, $7.4 \%-11.4 \%)$ at 10 years. This was not observed for nonmetastatic pancreatic and bronchopulmonary NETs, for which cancer-specific death exceeded noncancer death from the time of diagnosis (Figures 2 and 3 ).

We performed multivariable analyses to identify factors associated with the risk of cancer-specific death,

\section{B}

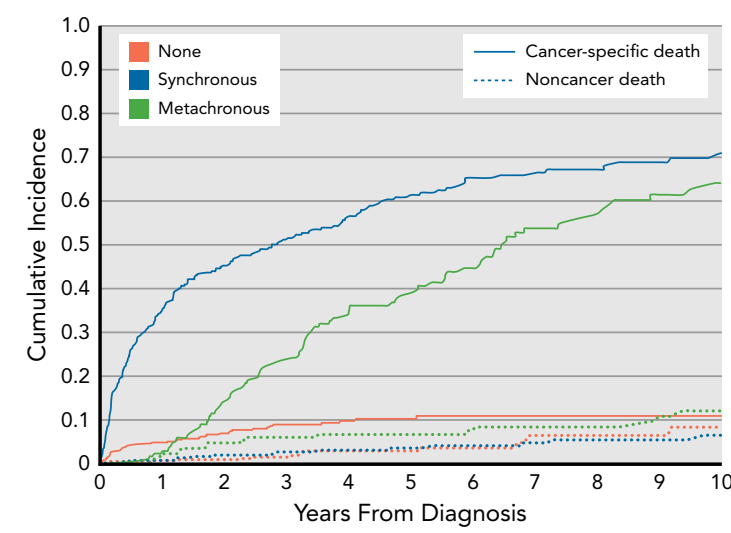

Number at risk

$\begin{array}{llllllllllll}\text { None } & 486 & 458 & 357 & 266 & 190 & 139 & 109 & 84 & 66 & 47 & 29\end{array}$ $\begin{array}{llllllllllll}\text { Synchronous } & 348 & 223 & 163 & 126 & 91 & 69 & 53 & 46 & 34 & 30 & 20 \\ & 160 & 129 & 111 & 85 & 74 & 56 & 39 & 33 & 25 & 18\end{array}$

Figure 2. Cancer-specific death and noncancer death cumulative incidence after pancreatic neuroendocrine tumor diagnosis for (A) all patients and (B) stratified by metastatic status. 
A

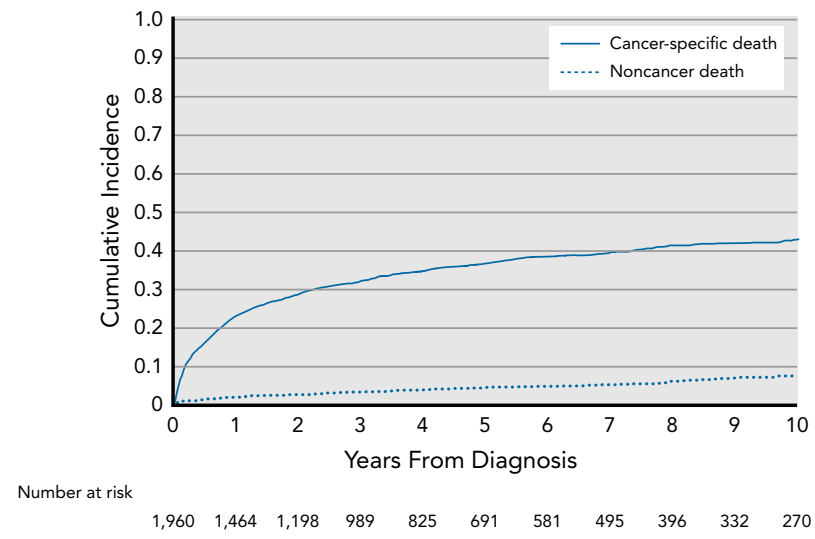

B

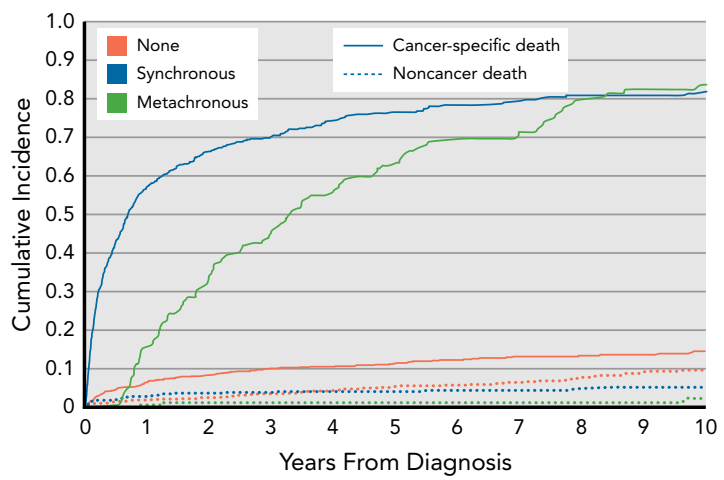

Number at risk

$\begin{array}{llllllllllll}\text { None } & 1,182 & 1,081 & 927 & 785 & 680 & 574 & 491 & 418 & 339 & 281 & 232\end{array}$ $\begin{array}{llllllllllrr}\text { Synchronous } & 609 & 243 & 164 & 121 & 83 & 71 & 53 & 47 & 37 & 35 & 27\end{array}$

$\begin{array}{llllllllllll}\text { Metachronous } & 169 & 143 & 109 & 85 & 63 & 49 & 38 & 33 & 22 & 18 & 13\end{array}$

Figure 3. Cancer-specific death and noncancer death cumulative incidence after bronchopulmonary neuroendocrine tumor diagnosis for (A) all patients and (B) stratified by metastatic status.

accounting for the competing risk of noncancer death (Table 2 and supplemental eTable 6). Advancing age was consistently associated with increased hazards of cancerspecific death in all NETs and when stratifying by NET group of bronchopulmonary, pancreatic, and gastroenteric. Female sex was associated with lower hazards of cancer-specific death compared with male sex for all NETs and stratified by NET group, although the association was not significant for pancreatic NETs. Higher material deprivation, indicating lower socioeconomic status, was independently associated with increased hazards of cancer-specific death. Higher comorbidity burden was associated with lower hazards of cancerspecific death, likely because of the observed higher hazards of noncancer death (sHR, 1.73; 95\% CI, 1.46-2.04), compared with patients with lower comorbidity burden. Both synchronous and metachronous metastases were independently associated with increased hazards of cancer-specific death in all NETs (sHR, 9.19 [95\% CI, 8.16-10.36] vs 6.55 [95\% CI, 5.84-7.60], respectively). This was also observed in stratified categories of NETs for bronchopulmonary, pancreatic, and gastroenteric NETs. Among all NETs, gastroenteric (sHR, 0.33; 95\% CI, 0.29-036) and pancreatic NETs (sHR, 0.74; 95\% CI, 0.65-0.85) presented independently lower hazards of cancer-specific death compared with bronchopulmonary NETs.

Factors associated with noncancer death were also examined (supplemental eTable 7). Advancing age, higher comorbidity burden, and increased material deprivation were associated with increased hazards of noncancer death. Both synchronous (sHR, 0.64; 95\% CI, 0.53-0.77) and metachronous (sHR, 0.68; 95\% CI, 0.52-0.89) metastatic disease was associated with lower hazards of noncancer death, compared with no metastases.

Finally, looking at noncancer cause of death by time period, 420 deaths ( $16.0 \%$ of deaths over the time period) were caused by cancer in $\leq 5$ years and 214 deaths $(8.2 \%$ of deaths over the time period) in $>5$ years from NET diagnosis. The breakdown of noncancer cause of death is presented in Figure 5. The most common causes of noncancer death were diseases of the heart and noncardiac vascular diseases.

\section{Discussion}

This population-based cohort study is the first to describe patterns of and factors associated with cancerspecific death after a NET diagnosis. We showed that patients with NETs experienced prolonged survival, and quantified how the risk of cancer-specific and noncancer death contributed to this. Patients with metastatic disease consistently had a largely higher risk of cancerspecific versus noncancer deaths. On the other hand, the risk of noncancer death exceeded that of cancerspecific death in some nonmetastatic NETs, namely gastric, small intestine, colonic, and rectal.

Data on cancer-specific mortality for NETs are scarce. ${ }^{11,13-15}$ Two studies developed nomograms to predict cancer-specific survival in all pancreatic NETs and in metastatic pancreatic NETs, but there was no specific information regarding risk estimates for cancerspecific survival or noncancer death. ${ }^{14,15}$ Two studies reported on cancer-specific survival for pancreatic NETs using Kaplan-Meier methods, which do not account for the competing risk of noncancer death. ${ }^{13}$ Competing-risk methods and assessment of noncancer death along with cancer-specific death are recommended to improve the 
A

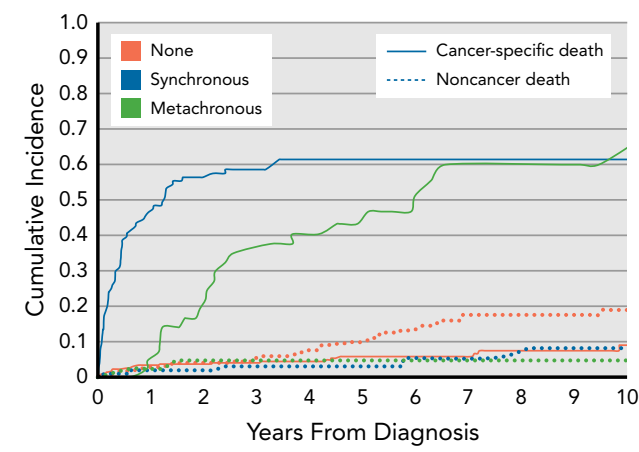

Number at risk

$\begin{array}{llllllllllll}\text { None } & 501 & 426 & 341 & 290 & 247 & 201 & 147 & 117 & 101 & 80 & 59\end{array}$ $\begin{array}{lllllllllllll}\text { Synchronous } & 354 & 333 & 274 & 237 & 205 & 167 & 124 & 86 & 81 & 65 & 46\end{array}$ $\begin{array}{llllllllllll}\text { Metachronous } & 104 & 54 & 39 & 31 & 23 & 19 & 14 & 14 & 13 & 9\end{array}$

\section{C}

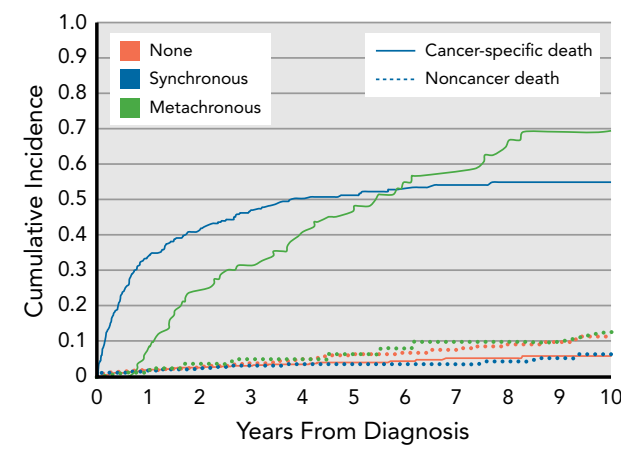

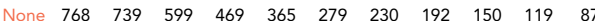
$\begin{array}{llllllllllll}\text { Synchronous } & 326 & 210 & 164 & 126 & 111 & 91 & 72 & 57 & 51 & 41 & 32\end{array}$ $\begin{array}{llllllllllll}\text { Metachronous } & 81 & 74 & 58 & 50 & 41 & 32 & 22 & 18 & 13 & 9 & 8\end{array}$
B

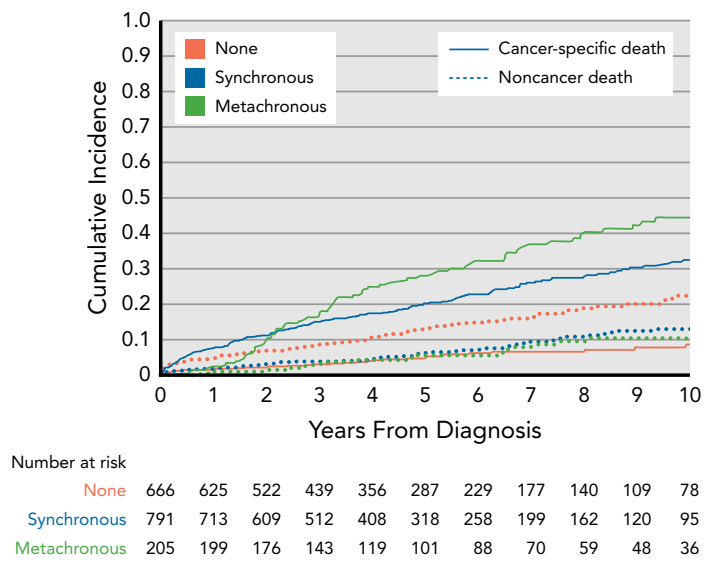

D

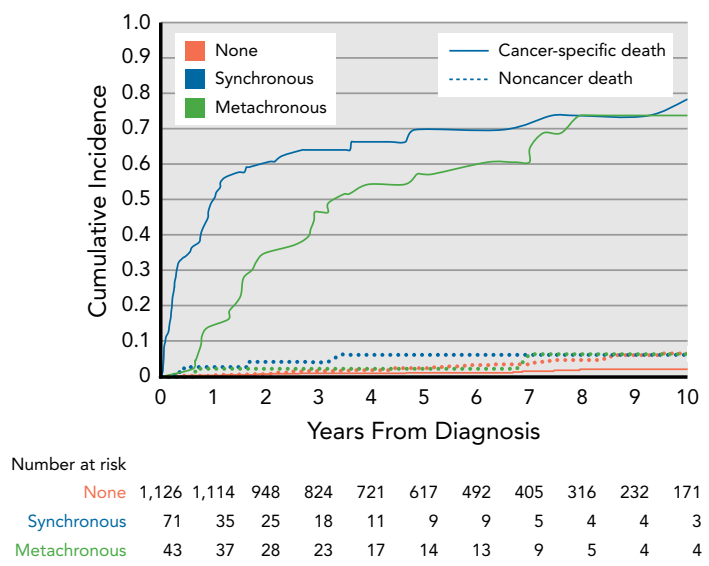

Figure 4. Cancer-specific death and noncancer death cumulative incidence after gastroenteric NET diagnosis stratified by metastatic status for (A) gastric, (B) small intestine, (C) colonic, and (D) rectal NETs.

Abbreviation: NET, neuroendocrine tumor.

reporting of cancer-specific mortality. ${ }^{33}$ A SEER study reported on NET recurrence patterns in the Medicare population (aged $\geq 65$ years), but although it indicated that patients with localized NETs at diagnosis have low risk of recurrence and therefore low likelihood of dying from NETs, it did not examine cancer-specific death. ${ }^{34}$ Our study provided long-term cancer and noncancer mortality outcomes for a contemporary cohort of NETs, further stratified by primary NET site and metastatic status, accounted for competing risks to avoid overestimation of the risk of cancer death, and offered a detailed analysis of prognostic factors for cancer-specific and noncancer death. ${ }^{30,31,35}$

Because of the unique biology of NETs, most patients experience prolonged survival. This potentially comes with associated longitudinal risk for noncancer death, which can complicate decisions regarding goals, modality, and sequencing of therapy, as well as individual patient counseling and supportive care. Thus, it is important to have data-driven insights for estimates of cancer-specific death across all patients and NET sites, which we have provided herein using population-based data representative of the full spectrum of patients encountered in contemporary clinical practice. Our results indicate that the probability of dying of cancer was greater than that of dying of noncancer causes overall. Those findings are modulated by NET type and metastatic status.

Patients with metastatic NETs had a much higher risk of dying from cancer than from other causes, consistent with the more aggressive nature of their disease. Accordingly, metastatic status was a strong independent prognostic factor of cancer death, but not of noncancer death. The curves for all NETs and those stratified by primary NET site showed an initial steep increase in cancer death in the first 2 years after diagnosis, indicating potentially more-aggressive NETs, consistent with known biology of advanced gastric, pancreatic, colonic, rectal, and bronchopulmonary 
Table 2. Multivariable Fine-Gray Model Showing Factors Associated With

\section{Cancer-Specific Death \\ Variable \\ sHR $(95 \% \mathrm{Cl})$}

Age at diagnosis, $y$

$<50 \quad$ Ref

\begin{tabular}{ll}
\hline $50-59$ & $1.60(1.38-1.87)$ \\
\hline $60-69$ & $2.11(1.82-2.44)$ \\
\hline$\geq 70$ & $3.33(2.89-3.84)$
\end{tabular}

Sex

Female

$0.82(0.75-0.89)$

Male

Ref

Comorbidity burden

Low (ADG 0-9)

Ref

High (ADG $\geq 10$ )

$0.90(0.82-0.99)$

Deprivation quintile

1 st (least deprived)

Ref

2nd

$1.07(0.94-1.23)$

$3 r d$

$1.03(0.90-1.18)$

4th

$1.09(0.96-1.24)$

5th (most deprived)

$1.24(1.09-1.41)$

Location of residence

\begin{tabular}{lc}
\hline Rural & $0.99(0.70-1.13)$ \\
\hline Urban & Ref
\end{tabular}

Year of diagnosis

2001-2008

Ref

2009-2015

$0.93(0.85-1.02)$

Primary NET site

Bronchopulmonary

Ref

Gastroenteric

$0.33(0.29-0.36)$

Pancreatic

$0.74(0.65-0.85)$

Others

$1.04(0.92-1.18)$

Metastatic status

None

Ref

Synchronous $^{\mathrm{a}}$

9.19 (8.16-10.36)

Metachronous $^{b}$

$6.66(5.84-7.60)$

Abbreviations: ADG, aggregated diagnosis group; NET, neuroendocrine tumor; sHR, subhazard ratio.

aSynchronous: $<6$ months from diagnosis.

bMetachronous: $\geq 6$ months from diagnosis.

NETs. Metastatic small intestine NETs presented a unique pattern of risk of cancer-specific death, with a gradual increase over 10 years, along with more favorable risk estimates than other primary NET sites. This can indicate a different and more chronic disease behavior, the availability of more treatment options, or higher levels of comfort among providers in treating those tumors. Nevertheless, the slow pace and lower incidence of cancer death in small intestine NETs should be taken into consideration. It supports longitudinal sequencing of therapy for metastatic small bowel NETs over years, as well as treatment strategies that consider long-term sequelae and quality of life, such as early resection of primary small intestinal NETs to prevent abdominal complications. ${ }^{36,37}$

In certain circumstances, cancer-specific death did not exceed noncancer death. The increase in incidence of NETs has previously been hypothesized as being related to diagnosis at an earlier stage and even possible overdiagnosis. ${ }^{4,5}$ There is ongoing debate regarding the best management of incidental NETs; although some support monitoring and nonoperative management, others propose a more aggressive surgical approach capitalizing on the opportunity to achieve cure and avoid subsequent NET spread and its associated mortality. In this setting, patterns of cancer-specific and noncancer death can provide important information to avoid overtreatment. Patients with nonmetastatic gastric, small intestine, colonic, and rectal NETs are less likely to die of cancer-specific versus other causes. However, the current analysis could not ascertain the contribution of therapy patterns to the risk of cancer-specific death. It is important that data on cancer-specific mortality be used along with specific patient and tumor information, such as age, comorbidity, endocrinopathy, tumor grade and size, and individual preferences, to optimize the design of personalized treatment strategies. It is acknowledged that various types of NETs do not have the same opportunity for therapy, ranging from potentially curative resection for localized small bowel NETs to multiple lines of systemic therapy for metastatic pancreatic NETs. Our observations warrant further investigation into cancerspecific mortality according to therapy and management patterns. The unique patterns observed also suggest that cancer-specific mortality should be used as an outcome when assessing treatment approaches for those types of NETs.

Finally, examination of factors associated with cancerspecific and noncancer-related death showed that efforts to address cancer-specific death in NETs should include special considerations for older adults and socioeconomically deprived patients to ensure they can access and receive care throughout their cancer journey. The association of advancing age with an increased risk of cancer death may be related to underlying increased vulnerability and frailty, but also risks of de-escalating cancer care in older adults who are underrepresented in clinical studies. ${ }^{38,39}$ Patients with a higher level of deprivation are known to exhibit different health-seeking behaviors and experience delayed diagnosis and access to care, which impact outcomes. ${ }^{32,40,41}$

Despite the inherent challenges associated with retrospective population-based studies, this examination 


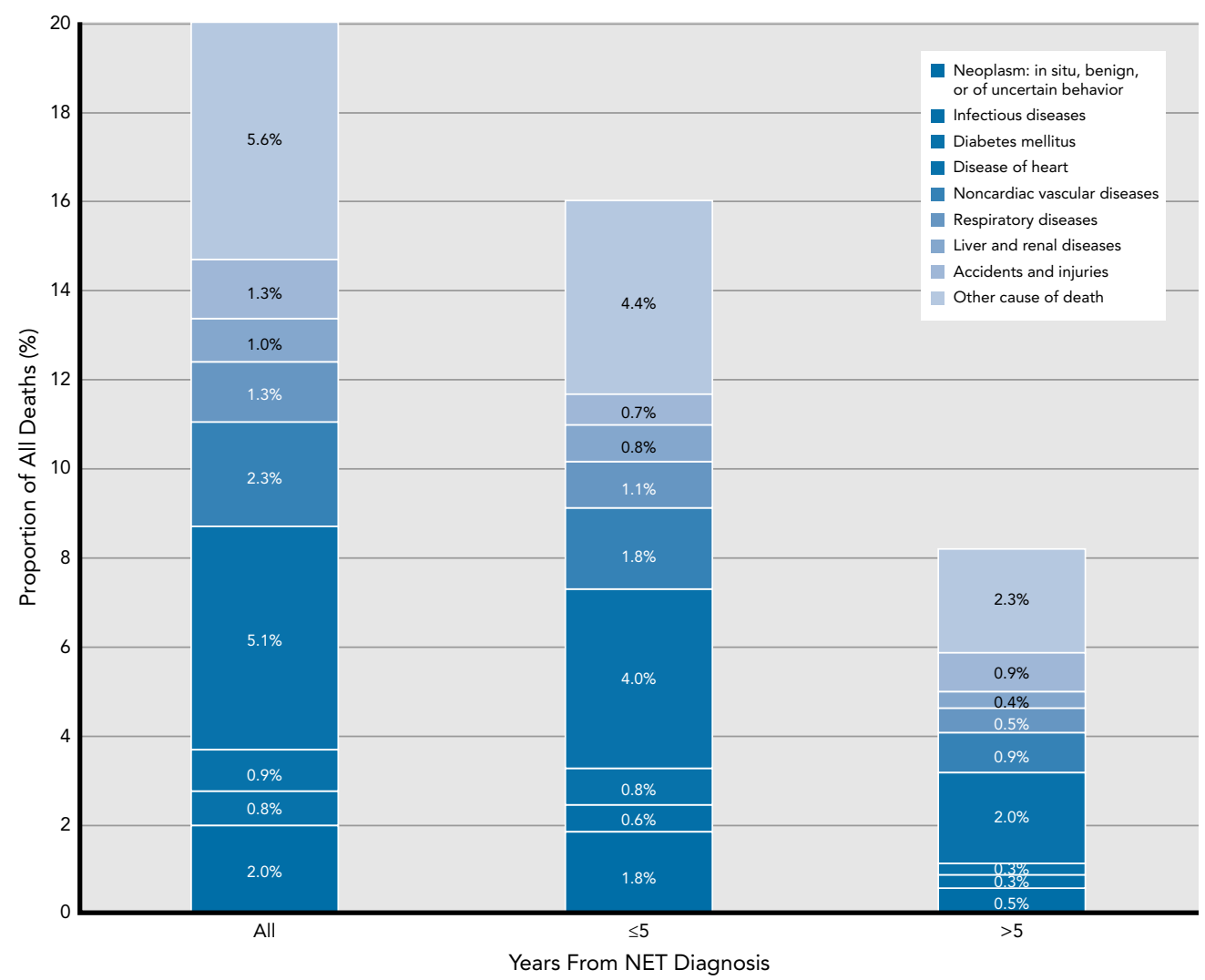

Figure 5. Causes of noncancer death after NET diagnosis.

Abbreviation: NET, neuroendocrine tumor.

provides a long-term detailed and robust appraisal of cancer-specific mortality among patients with NETs. However, the administrative data used was not collected specifically to address the current research question. We lacked some information regarding tumor characteristics, including stage and grade. We used metastases as a surrogate for advanced disease due to the unique biology of NETs and previous observations of metastatic status being the most significant prognostic factor. ${ }^{3}$ Using grade classification for the multivariable analysis and to stratify the results could have provided even more detailed information for clinical use, as could further stratification of primary NET site in models to examine factors associated with cancer-specific death. However, despite the overall large cohort, this resulted in too many levels for the covariates, with loss of levels of freedom and appropriateness of the regression model, such that primary NET sites were grouped into gastroenteric, pancreatic, bronchopulmonary, and others for the main model. Nevertheless, the population-based design of this study is a strength that allowed for a novel real-world assessment of the prognosis of patients diagnosed with NETs. These data also represent outcomes within a universal healthcare system, avoiding bias by insurance status-limited access.
We used high-quality linked administrative databases and definitions with known accuracy and reliability, which included comprehensive availability of cause of death and had limited missing data and measurement error.

\section{Conclusions}

In this population-based analysis, we reported cancerspecific mortality for patients diagnosed with NETs. Among all patients diagnosed with NETs, the risk of dying of cancer is higher than that of dying of other causes, especially in those with metastatic disease. Heterogeneity exists by primary NET site in patterns of cancer and noncancer death. This initial description of cancerspecific mortality for NETs can support patient counseling, clinical decision-making, discussion regarding clinical practice guidelines, and future trial designs.

Submitted May 6, 2020; final revision received September 9, 2020; accepted for publication October 7, 2020. Published online June 4, 2021.

Previous presentation: Part of this work was presented as a poster presentation at the 2020 ASCO Virtual Scientific Program; May 29-31, 2020. Abstract 4605

Author contributions: Study concept and design: Hallet, Law. Data abstraction: Hallet, Law, Mahar, Zuk, Zhao, Chan, Coburn. Data analysis and 
interpretation: All authors. Manuscript preparation: All authors. Critical revision: All authors.

Disclosures: Dr. Hallet and Dr. Law have reported receiving speaking honoraria from Ipsen Biopharmaceuticals Canada and Novartis Oncology, and travel support from the Baxter Corporation. Dr. Singh has reported receiving speaking honoraria from Ipsen Biopharmaceuticals Canada and Novartis Oncology, and research grants from Novartis Oncology and EMD Serono. Dr. Myrehaug has reported being the Principal Investigator on the NETTER-2 trial sponsored by AAA/Novartis. The remaining authors have disclosed that they have not received any financial consideration from any person or organization to support the preparation, analysis, results, or discussion of this article.

Funding: This study was supported by ICES, which is funded by an annual grant from the Ontario Ministry of Health and Long-Term Care (MOHLTC). This work was supported by the NANETS New Clinical Investigator Scholarship and an operating grant from the Canadian Institute of Health Research (FRN \#47301).

Disclaimer: The opinions, results, and conclusions reported in this article are those of the authors and are independent from the funding sources. No endorsement by ICES or the Ontario MOHLTC is intended or should be inferred. Parts of this material are based on data and information compiled and provided by $\mathrm{ClHI}$. However, the analyses, conclusions, opinions, and statements expressed herein are those of the author, and not necessarily those of $\mathrm{ClHI}$. Parts of this material are based on data and information provided by Cancer Care Ontario (CCO). The opinions, results, view, and conclusions reported in this paper are those of the authors and do not necessarily reflect those of $\mathrm{CCO}$. No endorsement by $\mathrm{CCO}$ is intended or should be inferred.

Correspondence: Julie Hallet, MD, MSc, Department of Surgery, Odette Cancer Centre - Sunnybrook Health Sciences Centre, 2075 Bayview Avenue, T2-102, Toronto, Ontario M4N 3M5, Canada. Email: julie.hallet@sunnybrook.ca

\section{References}

1. National Cancer Institute. Surveillance, Epidemiology, and End Results Program. Cancer Stat Facts.Accessed August 21, 2019. Available at: https://seer.cancer.gov/statfacts/

2. Kunz PL. Understanding neuroendocrine tumors: a NET gain. JAMA Oncol 2017;3:1343-1344.

3. Yao JC, Hassan M, Phan A, et al. One hundred years after "carcinoid": epidemiology of and prognostic factors for neuroendocrine tumors in 35,825 cases in the United States. J Clin Oncol 2008;26: 3063-3072.

4. Hallet J, Cukier M, Saskin R, Liu N. Exploring the rising incidence of neuroendocrine tumors: a population-based analysis of epidemiology, metastatic presentation, and outcomes. Cancer 2015;121:589-597.

5. Dasari A, Shen C, Halperin D, et al. Trends in the incidence, prevalence, and survival outcomes in patients with neuroendocrine tumors in the United States. JAMA Oncol 2017;3:1335-1338.

6. Yao JC, Fazio N, Singh S, et al. Everolimus for the treatment of advanced, non-functional neuroendocrine tumours of the lung or gastrointestinal tract (RADIANT-4): a randomised, placebo-controlled, phase 3 study. Lancet 2016;387:968-977.

7. Singh S, Moody L, Chan DL, et al. Follow-up recommendations for completely resected gastroenteropancreatic neuroendocrine tumors. JAMA Oncol 2018;4:1597-1604.

8. Halperin DM, Shen C, Dasari A, et al. Frequency of carcinoid syndrome at neuroendocrine tumour diagnosis: a population-based study. Lancet Oncol 2017;18:525-534.

9. Pavel M, Gross DJ, Benavent $M$, et al. Telotristat ethyl in carcinoid syndrome: safety and efficacy in the TELECAST phase 3 trial. Endocr Relat Cancer 2018;25:309-322.

10. Hemingway $H$, Croft $P$, Perel $P$, et al. Prognosis research strategy (PROGRESS) 1: a framework for researching clinical outcomes. BMJ 2013;346:e5595.

11. Ye $\mathrm{H}, \mathrm{Xu} \mathrm{HL}$, Shen $\mathrm{Q}$, et al. Palliative resection of primary tumor in metastatic nonfunctioning pancreatic neuroendocrine tumors. J Surg Res 2019;243:578-587.

12. Fraenkel M, Kim MK, Faggiano A, Valk GD. Epidemiology of gastroenteropancreatic neuroendocrine tumours. Best Pract Res Clin Gastroenterol 2012;26:691-703.

13. Powers BD, Rothermel LD, Fleming JB, et al. A survival analysis of patients with localized, asymptomatic pancreatic neuroendocrine tumors: no surgical survival benefit when examining appropriately selected outcomes.J Gastrointest Surg 2020;24:2773-2779

14. Li Z, Du S, Feng W, et al. Competing risks and cause-specific mortality in patients with pancreatic neuroendocrine tumors. Eur J Gastroenterol Hepatol 2019;31:749-755.

15. He CB, Zhang Y, Cai ZY, et al. The impact of surgery in metastatic pancreatic neuroendocrine tumors: a competing risk analysis. Endocr Connect 2019;8:239-251.

16. Benchimol El, Smeeth L, Guttmann A, et al. The REporting of studies Conducted using Observational Routinely-collected health Data (RECORD) statement. PLOS Med 2015;12:e1001885.

17. Iron Z, Zagorski BM, Sykora K. Living and Dying in Ontario: An Opportunity for Improved Health Information. ICES Investigative Report. Toronto, Ontario, Canada: Institute for Clinical Evaluative Sciences (ICES); 2008.

18. Clarke EA, Marrett LD, Kreiger N. Cancer registration in Ontario: a computer approach. IARC Sci Publ 1991;(95):246-257.
19. Robles SC, Marrett LD, Clarke EA, et al. An application of capturerecapture methods to the estimation of completeness of cancer registration. J Clin Epidemiol 1988;41:495-501.

20. Government of Canada. Canada Health Act. Accessed August 21, 2019. Available at: https://www.canada.ca/en/health-canada/services/ health-care-system/canada-health-care-system-medicare/canadahealth-act.html

21. Hallet J, Law CHL, Saskin R, Liu N. Rural-urban disparities in incidence and outcomes of neuroendocrine tumors: a population-based analysis of 6271 cases. Cancer 2015;121:2214-2221.

22. Brenner DR, Tammemägi MC, Bull SB, et al. Using cancer registry data: agreement in cause-of-death data between the Ontario Cancer Registry and a longitudinal study of breast cancer patients. Chronic Dis Can 2009;30: 16-19.

23. Afifi AM, Saad AM, Al-Husseini MJ, et al. Causes of death after breast cancer diagnosis: a US population-based analysis. Cancer 2020;126:1559-1567.

24. Karlj B. Measuring "rurality" for purposes of health-care planning: an empirical measure for Ontario. Ont Med Rev 2009;33:52.

25. Krieger N. Overcoming the absence of socioeconomic data in medical records: validation and application of a census-based methodology. Am J Public Health 1992;82:703-710.

26. Matheson FI, Dunn JR, Smith KLW, et al. Development of the Canadian Marginalization Index: a new tool for the study of inequality. Can J Pub Health 2012;103:S12-16.

27. Reid RJ, Roos NP, MacWilliam L, et al. Assessing population health care need using a claims-based ACG morbidity measure: a validation analysis in the Province of Manitoba. Health Serv Res 2002;37:1345-1364

28. Reid RJ, MacWilliam L, Verhulst L, et al. Performance of the ACG case-mix system in two Canadian provinces. Med Care 2001;39:86-99.

29. Weiner JP, Starfield BH, Steinwachs DM, et al. Development and application of a population-oriented measure of ambulatory care case-mix. Med Care 1991;29:452-472.

30. Austin PC, Lee DS, Fine JP. Introduction to the analysis of survival data in the presence of competing risks. Circulation 2016;133:601-609.

31. Austin PC, Fine JP. Practical recommendations for reporting Fine-Gray model analyses for competing risk data. Stat Med 2017;36: 4391-4400.

32. Hallet J, Coburn NG, Singh S, et al. Access to care and outcomes for neuroendocrine tumours: does socioeconomic status matter? Curr Oncol 2018;25:e356-364.

33. Wissing MD, Greenwald ZR, Franco EL. Improving the reporting of cancerspecific mortality and survival in research using cancer registry data. Cancer Epidemiol 2019;59:232-235.

34. Shen C, Dasari A, Chu Y, et al. Clinical, pathological, and demographic factors associated with development of recurrences after surgical resection in elderly patients with neuroendocrine tumors. Ann Oncol 2017; 28:1582-1589.

35. Putter H, Fiocco M, Geskus RB. Tutorial in biostatistics: competing risks and multi-state models. Stat Med 2007;26:2389-2430.

36. Citterio D, Pusceddu S, Facciorusso A, et al. Primary tumour resection may improve survival in functional well-differentiated neuroendocrine tumours metastatic to the liver. Eur J Surg Oncol 2017;43:380-387.

37. Daskalakis $K$, Karakatsanis A, Stålberg $P$, et al. Clinical signs of fibrosis in small intestinal neuroendocrine tumours. Br J Surg 2016;104:69-75. 
38. Townsley CA, Selby R, Siu LL. Systematic review of barriers to the recruitment of older patients with cancer onto clinical trials. J Clin Oncol 2005;23:3112-3124.

39. Hurria A, Dale W, Mooney M, et al. Designing therapeutic clinical trials for older and frail adults with cancer: U13 conference recommendations. $\mathrm{J}$ Clin Oncol 2014;32:2587-2594.
40. Booth CM, Li G, Zhang-Salomons J, Mackillop WJ. The impact of socioeconomic status on stage of cancer at diagnosis and survival: a population-based study in Ontario, Canada. Cancer 2010;116: 4160-4167.

41. Woods LM, Rachet B, Coleman MP. Origins of socio-economic inequalities in cancer survival: a review. Ann Oncol 2006;17:5-19.

\section{RESOURCES TO EDUCATE YOU AND YOUR TEAM}

Interactive slide decks along with comprehensive speaker notes are now available on several new topics.

\section{NEW TOPICS IN OUR LIBRARY}

Biosimilars 
Supplemental online content for:

\section{Risk of Cancer-Specific Death for Patients Diagnosed With Neuroendocrine Tumors: A Population-Based Analysis}

Julie Hallet, MD, MSc; Calvin Law, MD, MPH; Simron Singh, MD, MPH; Alyson Mahar, PhD; Sten Myrehaug, MD; Victoria Zuk, MSc; Haoyu Zhao, MPH; Wing Chan, MPH; Angela Assal, MD, MSc; and Natalie Coburn, MD, MPH

J Natl Compr Canc Netw 2021;19(8):935-944

eFigure 1: Cancer-Specific Death After NET Diagnosis

eFigure 2: Cancer-Specific Death After Gastroenteric NET Diagnosis

eTable 1: Data Sources

eTable 2: Coding Strategy Used to Identify Patients Diagnosed With NETs and Determine Tumor Characteristics eTable 3: Definition of Noncancer Cause of Death Categories

eTable 4: Covariate Definitions

eTable 5: Characteristics of Included Patients Stratified by Primary NET Site

eTable 6: Multivariable Fine-Gray Model Showing Factors Associated With Cancer-Specific Death Stratified by Primary NET Site

eTable 7: Multivariable Fine-Gray Model Showing Factors Associated With Noncancer Death 
Hallet et al - 1

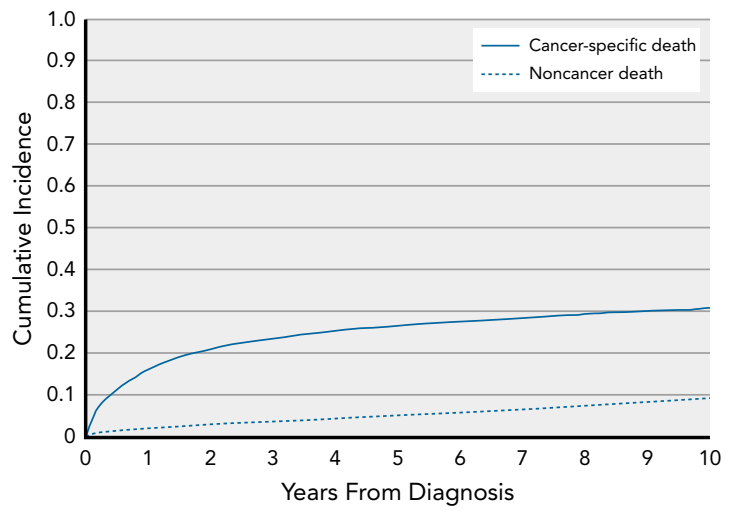

eFigure 1. Cancer-specific death after NET diagnosis in sensitivity analysis excluding patients with non-NET cancer diagnosis after NET diagnosis $(n=7,942)$.

Abbreviation: NET, neuroendocrine tumor. 
A

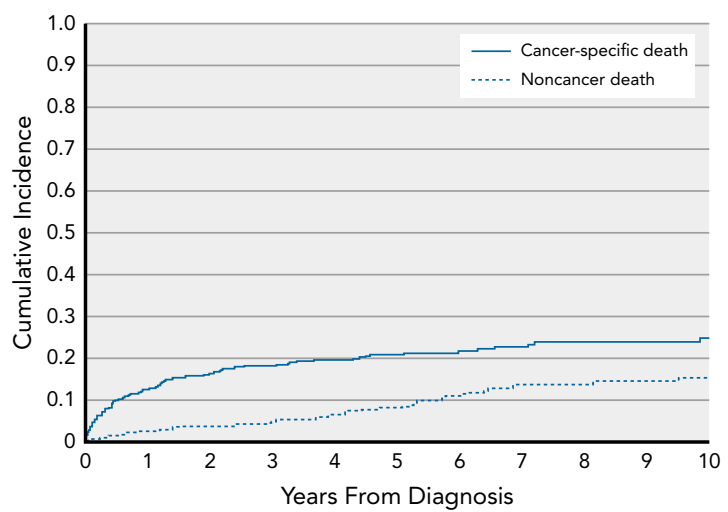

Number at risk

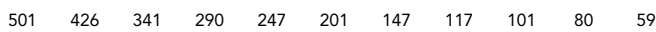

C

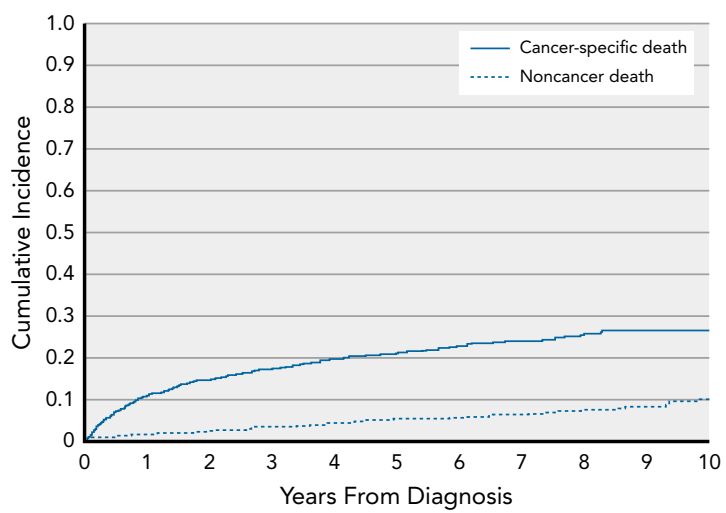

Number at risk

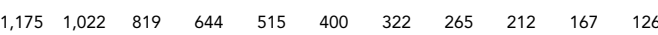

B

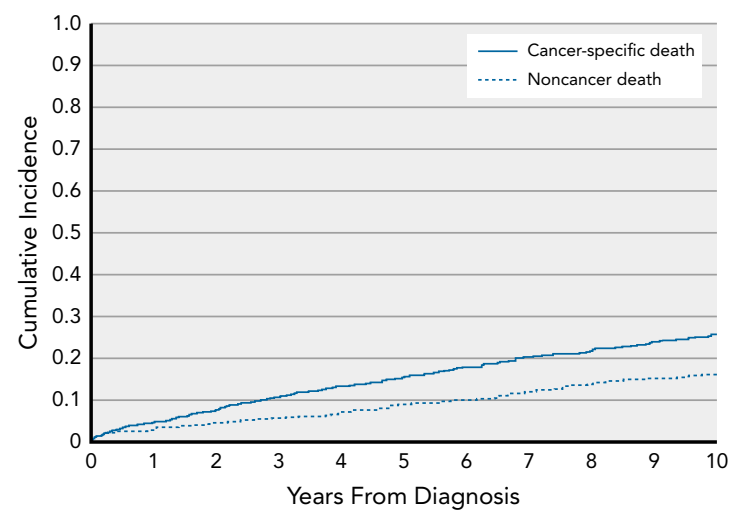

Number at risk

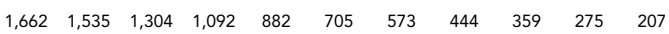

D

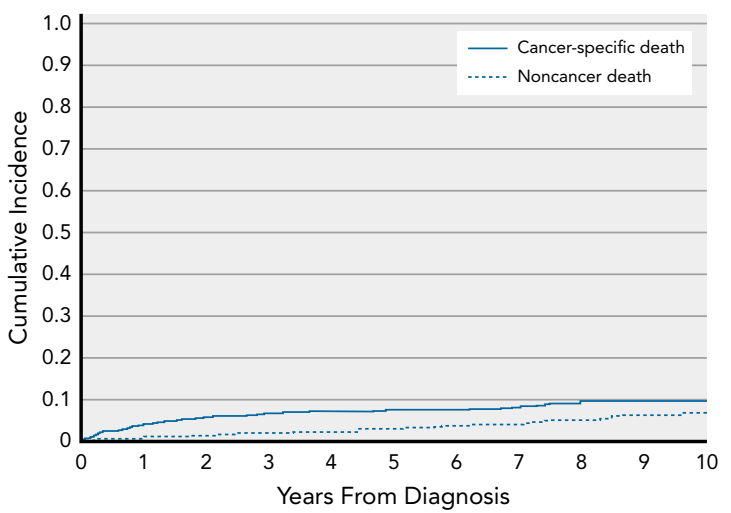

Number at risk

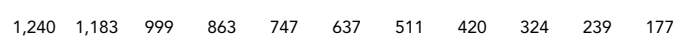

eFigure 2. Cancer-specific death after gastroenteric NET diagnosis for (A) gastric, (B) small intestine, (C) colonic, and (D) rectal NETs. Abbreviation: NET, neuroendocrine tumor. 
eTable 1. Data Sources

Database

OCR

ALR of $\mathrm{CCO}$

RPDB

ORG

OHIP database

ODB database

CIHI-DAD and CIHI-SDS
ON-Marg

\section{Description}

A passive, provincial registry all incident cancer diagnoses in Ontario. It includes $96 \%$ of cancer diagnoses in the province. Information included in the registry: cancer topography and morphology/histology, and details on diagnosis (eg, types of contributing information to the diagnosis, dates).

CCO maintains a database of cancer-specific services, including consultations, chemotherapy, and radiotherapy provided by regional cancer centers in the province. Because all radiotherapy is delivered at RCCs, it is a complete source of information However, because not all patients with cancer who receive surgery or chemotherapy visit an RCC, it cannot be used as a population data sources for those treatments.

An ICES database derived from all administrative data sources and provides demographic data including age, patient residence, vital status, date of last contact with the healthcare system, and OHIP eligibility.

Contains gold standard vital status data for all Ontarians. According to the Vital Statistics Act, it is mandatory to register all deaths occurring in the province.

A specialized database using Census data to profile relative area-level marginalization dependency, deprivation, ethnic concentration, and instability at various geographic levels in Ontario.

Contains all physician billing data including information on diagnoses as well as services provided, such as receipt of surgery, chemotherapy, and radiotherapy.

Contains all information for prescription drug claims for individuals covered by the provincial plan (all individuals aged $\geq 65$ years), including type of medication, dose, date of prescription filling, and duration of treatment.

Mandatory reporting systems that provide information on hospital admissions and same-day surgeries, including diagnoses, procedures, and length of stay.

Abbreviations: ALR, Activity Level Report; CCO, Cancer Care Ontario; CIHI-DAD, Canadian Institute of Health Information Discharge Abstract Database; CIHI-SDS Canadian Institute of Health Information Same-Day Surgery; OCR, Ontario Cancer Registry; ODB, Ontario Drug Benefit; OHIP, Ontario Health Insurance Plan;

ON-Marg, Ontario Marginalization Index; ORG, Ontario Registrar General; RCC, regional cancer center; RPDB, Registered Patient Database. 


\section{eTable 2. Coding Strategy Used to Identify Patients Diagnosed With NETs and Determine Tumor Characteristics}

\section{Identify NETs (ICD-O-3)}

\begin{tabular}{|c|c|}
\hline 81503 & Islet cell carcinoma \\
\hline 81501 & Islet cell tumor, NOS \\
\hline 81510 & Insulinoma, NOS \\
\hline 81513 & Insulinoma, malignant \\
\hline 81521 & Glucagonoma \\
\hline 81523 & Glucagonoma, malignant \\
\hline 81531 & Gastrinoma \\
\hline 81533 & Gastrinoma, malignant \\
\hline 81543 & Mixed islet-cell/exocrine adenocarcinoma \\
\hline 81551 & VIPoma \\
\hline 81553 & VIPoma, malignant \\
\hline 81561 & Somatostatinoma \\
\hline 81563 & Somatostatinoma, malignant \\
\hline 81571 & Enteroglucagonoma \\
\hline 81573 & Entroglucagonomam, malignant \\
\hline 82401 & $\begin{array}{l}\text { Carcinoid tumor of uncertain malignant } \\
\text { potential }\end{array}$ \\
\hline 82403 & Carcinoid tumor, NOS \\
\hline 82413 & Enterochromaffin-like cell carcinoid \\
\hline 82421 & Enterochromaffin-like cell tumors, NOS \\
\hline 82423 & Enterochromaffin-like cell tumors, malignant \\
\hline 82443 & Composite carcinoid \\
\hline 82453 & Adenocarcinoid \\
\hline 82451 & Tubular carcinoid \\
\hline 8463 & Neuroendocrine carcinoma \\
\hline 82493 & Atypical carcinoid \\
\hline \multicolumn{2}{|c|}{ Exclusions (ICD-O-3) } \\
\hline 80023 & Malignant tumor, small cell type \\
\hline 80400 & Tumorlet \\
\hline 80413 & Small cell carcinoma, NOS \\
\hline 80423 & Oat cell carcinoma \\
\hline 80433 & Small cell carcinoma, NOS, fusiform cell type \\
\hline 80443 & Small cell carcinoma, intermediate cell \\
\hline 80453 & Combined small cell carcinoma \\
\hline 80133 & $\begin{array}{l}\text { Large cell neuroendocrine carcinoma of the } \\
\text { lung }\end{array}$ \\
\hline 87000 & Pheochromocytoma, NOS \\
\hline 87003 & Pheochromocytoma, malignant \\
\hline 86801 & Paraganglioma \\
\hline 86803 & Paraganglioma, malignant \\
\hline 86931 & Extra-adrenal paraganglioma \\
\hline 86933 & Extra-adrenal paraganglioma, malignant \\
\hline 85103 & Medullary carcinoma of the thyroid \\
\hline
\end{tabular}

(continued)
eTable 2. Coding Strategy Used to Identify Patients Diagnosed With NETs and

Determine Tumor Characteristics (cont.)

\section{Exclusions (ICD-O-3) - cont.}

\begin{tabular}{ll|}
\hline 80000 & Neoplasm, benign \\
\hline 80001 & $\begin{array}{l}\text { Neoplasm, uncertain whether benign or } \\
\text { malignant }\end{array}$ \\
\hline 80003 & Neoplasm, malignant \\
\hline 80100 & Epithelial tumor, benign \\
\hline 80702 & Squamous cell carcinoma, in situ, NOS \\
\hline 80703 & Squamous, cell carcinoma, NOS \\
\hline 80706 & Squamous cell carcinoma, metastatic, NOS \\
\hline 81400 & Adenoma, NOS \\
\hline 81401 & Atypical adenoma \\
\hline 83413 & Papillary microcarcinoma \\
\hline 84813 & Mucinous producing adenocarcinoma \\
\hline 85002 & Intraductal carcinoma, noninfiltrating, NOS \\
\hline 85003 & Infiltrating duct carcinoma, NOS \\
\hline 93643 & Peripheral neuroectodermal tumor \\
\hline 93703 & Chordoma \\
\hline 82433 & Goblet cell carcinoid \\
\hline efine primary tumor type (ICD-O-3 topography codes) \\
\hline C16* & Stomach \\
\hline C17* & Small intestine \\
\hline C18*, C19* & Large intestine \\
\hline C20* & Rectum \\
\hline All others & Pancreas \\
\hline & Bronchus \\
\hline Others \\
\hline 8
\end{tabular}

Abbreviations: NET, neuroendocrine tumor; NOS, not otherwise specified; VIPoma, vasoactive intestinal peptide tumor. 


\section{eTable 3. Definition of Noncancer Cause of Death Categories}

\begin{tabular}{|c|c|c|c|}
\hline Category & Noncancer Causes of Death & ICD-10 Corresponding Codes & Cause of Death Definition \\
\hline \multirow[t]{2}{*}{ Benign tumors } & \multirow[t]{2}{*}{ In situ, benign or unknown behavior neoplasms } & D00-D09 & In situ neoplasms \\
\hline & & D10-D36 & Benign neoplasms \\
\hline Diabetes & Diabetes mellitus & E10-E14 & Diabetes mellitus \\
\hline Infectious diseases & Septicemia & A40-A41 & Sepsis \\
\hline \multirow[t]{11}{*}{ Noncardiac vascular diseases } & \multirow[t]{2}{*}{ Hypertension without heart disease } & 110 & Essential (primary) hypertension \\
\hline & & 112 & Hypertensive renal disease \\
\hline & \multirow[t]{3}{*}{ Cerebrovascular disease } & $160-162$ & Nontraumatic intracranial hemorrhage \\
\hline & & 163 & Cerebral infarction \\
\hline & & 164 & $\begin{array}{l}\text { Stroke, not specified as hemorrhage or } \\
\text { infarction }\end{array}$ \\
\hline & Atherosclerosis & 170 & Atherosclerosis \\
\hline & Aortic aneurysm and dissection & 171 & Aortic aneurysm and dissection \\
\hline & \multirow[t]{4}{*}{ Other diseases of arteries, arterioles, capillaries } & $172-173$ & $\begin{array}{l}\text { Other aneurysm and dissection or other } \\
\text { peripheral vascular diseases }\end{array}$ \\
\hline & & 174 & Arterial embolism and thrombosis \\
\hline & & 177 & Other disorders of arteries and arterioles \\
\hline & & 178 & Diseases of capillaries \\
\hline \multirow[t]{2}{*}{ Respiratory diseases } & Pneumonia and influenza & J09-J18 & Influenza and pneumonia \\
\hline & Chronic obstructive pulmonary disease & $\mathrm{J} 40-\mathrm{J} 42$ & Bronchitis \\
\hline \multirow{5}{*}{ Liver and kidney diseases } & \multirow[t]{5}{*}{ Nephritis, nephrotic syndrome, and nephrosis } & N00-N07 & Glomerular diseases \\
\hline & & N17-N19 & Renal failure \\
\hline & & N25 & $\begin{array}{l}\text { Disorders resulting from impaired renal tubular } \\
\text { function }\end{array}$ \\
\hline & & N26 & Unspecified contracted kidney \\
\hline & & N27 & Small kidney of unknown cause \\
\hline \multirow[t]{5}{*}{ Accidents and self-harm } & \multirow[t]{3}{*}{ Accidents and adverse effects } & V01-V99 & Transport accidents \\
\hline & & W00-X59 & Other external causes of accidental injury \\
\hline & & Y85-Y86 & $\begin{array}{l}\text { Sequelae of transport accidents or other } \\
\text { accidents }\end{array}$ \\
\hline & \multirow[t]{2}{*}{ Suicide and self-inflicted injury } & X60-X84 & Intentional self-harm \\
\hline & & Y87 & $\begin{array}{l}\text { Sequelae of intentional self-harm, assault, and } \\
\text { events of undetermined intent }\end{array}$ \\
\hline
\end{tabular}

(continued on next page) 
eTable 3. Definition of Noncancer Cause of Death Categories (cont.)

\begin{tabular}{|c|c|c|c|}
\hline Category & Noncancer Causes of Death & ICD-10 Corresponding Codes & Cause of Death Definition \\
\hline Alzheimer & Alzheimer & G30 & Alzheimer disease \\
\hline \multirow{16}{*}{\multicolumn{2}{|c|}{ Diseases of the heart }} & 100-102 & Acute rheumatic fever \\
\hline & & 105-109 & Chronic rheumatic heart diseases \\
\hline & & 111 & Hypertensive heart disease \\
\hline & & 113 & Hypertensive heart and renal disease \\
\hline & & |20-|25 & Ischemic heart diseases \\
\hline & & |26-|28 & $\begin{array}{l}\text { Pulmonary heart disease and diseases of } \\
\text { pulmonary circulation }\end{array}$ \\
\hline & & 130-132 & Diseases of pericardium \\
\hline & & 133 & Acute and subacute endocarditis \\
\hline & & 134-139 & Nonrheumatic valve disorders \\
\hline & & $140-141$ & Myocarditis \\
\hline & & $142-143$ & Cardiomyopathy \\
\hline & & $144-145$ & Conduction disorders \\
\hline & & 146 & Cardiac arrest \\
\hline & & $147-149$ & Arrythmias \\
\hline & & 150 & Heart failure \\
\hline & & 151 & $\begin{array}{l}\text { Complications and ill-defined descriptions of } \\
\text { heart disease }\end{array}$ \\
\hline \multirow[t]{2}{*}{ Other noncancer } & Symptoms, signs, and ill-defined conditions & R00-R99 & $\begin{array}{l}\text { Symptoms, signs, abnormal results of clinical or } \\
\text { other investigative procedures, and ill-defined } \\
\text { conditions regarding which no diagnosis } \\
\text { classifiable elsewhere is recorded }\end{array}$ \\
\hline & Other cause of death & \multicolumn{2}{|c|}{ All others not included in any of the above } \\
\hline
\end{tabular}




\section{eTable 4. Covariate Definitions}

\begin{tabular}{|c|c|c|c|c|}
\hline Variable & Definition & Source & Type & Analysis Format \\
\hline \multirow[t]{2}{*}{ Age } & Age at diagnosis & OCR & Categorical & $\begin{array}{l}<50 \\
50-59 \\
60-69 \\
\geq 70\end{array}$ \\
\hline & & & Continuous & Years \\
\hline Rural residence & $\begin{array}{l}\text { Determined with postal code of residence as } \\
\text { per national census definition of a community } \\
<10,000 \text { people }^{3}\end{array}$ & RPDB & Dichotomous & Urban/Rural \\
\hline Comorbidity burden & $\begin{array}{l}\text { Measured using the Johns Hopkins Adjusted } \\
\text { Clinical Groups system score based on health } \\
\text { services use with a } 24 \text {-month look-back } \\
\text { window before the date of cancer diagnosis } \\
\text { whereby the } 32 \text { ADGs are summed to create a } \\
\text { total score }{ }^{4,5}\end{array}$ & $\begin{array}{l}\text { CIHI-DAD } \\
\text { CIHI-SDS } \\
\text { OHIP }\end{array}$ & Dichotomous & $\begin{array}{l}<10 \\
\geq 10\end{array}$ \\
\hline Primary NET site & $\begin{array}{l}\text { Type of primary NET on ICD-O-3 codes } \\
\text { (supplemental eTable 2) }\end{array}$ & OCR & Categorical & $\begin{array}{l}\text { Gastric } \\
\text { Small intestinal } \\
\text { Colonic } \\
\text { Rectal } \\
\text { Pancreatic } \\
\text { Bronchopulmonary } \\
\text { Others }\end{array}$ \\
\hline Metastatic status & Presence of metastases using ICD-O-3 codes & $\begin{array}{l}\text { OCR } \\
\text { CIHI-DAD } \\
\text { CIHI-SDS } \\
\text { NACRS }\end{array}$ & Categorical & $\begin{array}{l}\text { No metastases } \\
\text { Synchronous } \\
\text { Metachronous }\end{array}$ \\
\hline
\end{tabular}

Abbreviations: ADG, aggregated diagnosis group; CIHI-DAD, Canadian Institute of Health Information Discharge Abstract Database; CIHI-SDS, Canadian Institute of Health Information Same-Day Surgery; NACRS, national ambulatory care reporting system; NET, neuroendocrine tumor; OCR, Ontario Cancer Registry; OHIP, Ontario Health Insurance Plan; ON-Marg, Ontario Marginalization Index; RPDB, Registered Patient Database.

\section{References}

1. Matheson FI, Dunn JR, Smith KLW, et al. Development of the Canadian Marginalization Index: a new tool for the study of inequality. Can J Pub Health 2012;103(Suppl 2):S12-16.

2. Krieger N. Overcoming the absence of socioeconomic data in medical records: validation and application of a census-based methodology. Am J Public Health 1992 ; 82:703-710.

3. Du Plessis V, Beshiri R, Bollman R. Definitions of "rural." Rural Small Town Canada Anal Bull 2013;3:1-43.

4. Reid RJ, Roos NP, MacWilliam L, et al. Assessing population health care need using a claims-based ACG morbidity measure: a validation analysis in the Province of Manitoba. Health Serv Res 2002;37:1345-1364.

5. Reid RJ, MacWilliam L, Verhulst L, et al. Performance of the ACG case-mix system in two Canadian provinces. Med Care 2001;39:86-99. 


\begin{tabular}{|c|c|c|c|c|c|c|c|}
\hline \multicolumn{8}{|l|}{ Age at diagnosis, y } \\
\hline$<50$ & $236(23.6)$ & $96(19.2)$ & $328(16.7)$ & $426(36.3)$ & $236(14.2)$ & $348(28.1)$ & $192(18.0)$ \\
\hline$\geq 70$ & $225(22.5)$ & $188(37.5)$ & $692(35.3)$ & $271(23.1)$ & $545(32.8)$ & $161(13.0)$ & $433(40.5)$ \\
\hline \multicolumn{8}{|l|}{ Sex } \\
\hline Female & $448(44.8)$ & $251(50.1)$ & $1,148(58.6)$ & $617(52.5)$ & $748(45.0)$ & $589(47.5)$ & $522(48.9)$ \\
\hline Male & $553(55.2)$ & $250(49.9)$ & $812(41.4)$ & $558(47.5)$ & $914(55.0)$ & $651(52.5)$ & $546(51.1)$ \\
\hline \multicolumn{8}{|l|}{ Location of residence } \\
\hline Missing & $10(1.0)$ & $11(2.2)$ & $22(1.1)$ & $11(0.9)$ & $22(1.3)$ & $12(1.0)$ & $14(1.3)$ \\
\hline Rural & $76(7.6)$ & $35(7.0)$ & $223(11.4)$ & $102(8.7)$ & $186(11.2)$ & $83(6.7)$ & $119(11.1)$ \\
\hline Urban & $915(91.4)$ & 455 (90.8) & 1,715 & $1,062(90.4)$ & $1,454(87.5)$ & $1,145(92.3)$ & $935(87.5)$ \\
\hline \multicolumn{8}{|l|}{ Material deprivation quintile } \\
\hline Missing & $7(0.7)$ & $11(2.2)$ & $22(1.1)$ & $11(0.9)$ & $20(1.2)$ & $11(0.9)$ & $11(1.0)$ \\
\hline 1st (least deprived) & $204(20.4)$ & $81(16.2)$ & $352(18.0)$ & $261(22.2)$ & $328(19.7)$ & $226(18.2)$ & $196(18.4)$ \\
\hline 2nd & $211(21.1)$ & $90(18.0)$ & $386(19.7)$ & $228(19.4)$ & $338(20.3)$ & $252(20.3)$ & $199(18.6)$ \\
\hline $3 r d$ & $183(18.3)$ & $102(20.4)$ & $388(19.8)$ & $212(18.0)$ & $323(19.4)$ & $261(21.0)$ & $191(17.9)$ \\
\hline None & $486(48.6)$ & $354(70.7)$ & $1,182(60.3)$ & $768(65.4)$ & $666(40.1)$ & $1,126(90.8)$ & $396(37.1)$ \\
\hline Synchronous ${ }^{\mathrm{a}}$ & $348(34.8)$ & $104(20.8)$ & $609(31.1)$ & $326(27.7)$ & $791(47.6)$ & $71(5.7)$ & $505(47.3)$ \\
\hline Metachronous ${ }^{b}$ & $167(16.7)$ & $43(8.6)$ & $169(8.6)$ & $81(6.9)$ & $205(12.3)$ & $43(3.5)$ & $167(15.6)$ \\
\hline Median duration of follow-up (IQR), mo & $36(11-85)$ & $36(17-64)$ & $45(18-77)$ & $51(27-87)$ & $41(19-77)$ & $61(29-97)$ & $19(5-58)$ \\
\hline Death of any cause during follow-up & $869(44.3)$ & $413(41.3)$ & $167(33.3)$ & $500(30.1)$ & $332(28.3)$ & $153(12.3)$ & $687(64.3)$ \\
\hline
\end{tabular}

Abbreviations: ADG, aggregated diagnosis group; IQR, interquartile range; NET, neuroendocrine tumor.

aSynchronous: $<6$ months from diagnosis.

bMetachronous: $\geq 6$ months from diagnosis. 


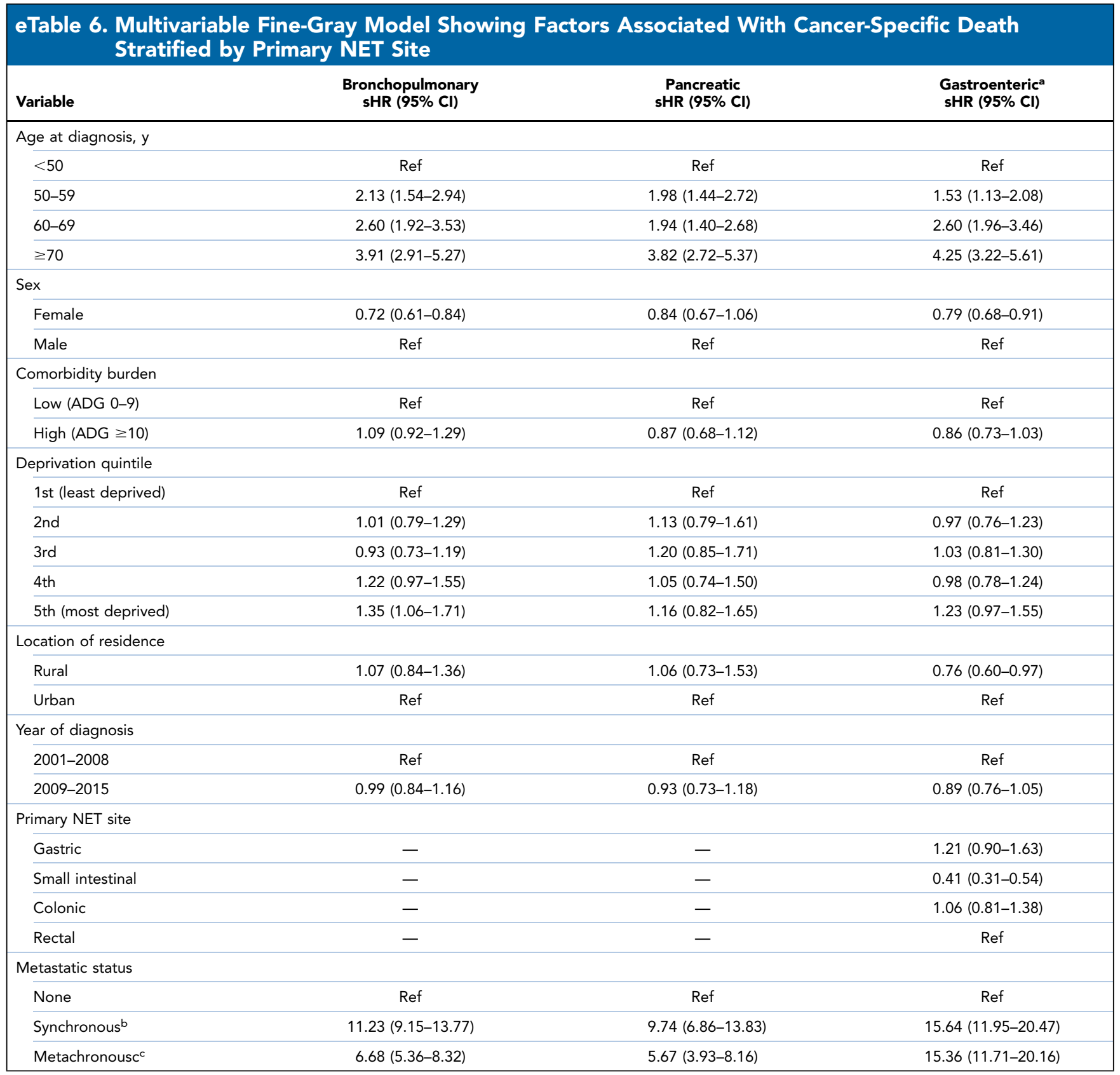

Abbreviations: ADG, aggregated diagnosis group; NET, neuroendocrine tumor; sHR, subhazard ratio.

aGastroenteric: stomach, small intestine, colon, rectum.

bSynchronous: $<6$ months from diagnosis.

cMetachronous: $\geq 6$ months from diagnosis. 


\section{eTable 7. Multivariable Fine-Gray Model Showing Factors Associated With Noncancer Death}

\begin{tabular}{|c|c|c|c|c|}
\hline Variable & $\begin{array}{l}\text { All Patients } \\
\text { sHR (95\% Cl) }\end{array}$ & $\begin{array}{l}\text { Bronchopulmonary } \\
\text { sHR }(95 \% \mathrm{Cl})\end{array}$ & $\begin{array}{c}\text { Pancreatic } \\
\text { sHR (95\% Cl) }\end{array}$ & $\begin{array}{l}\text { Gastroenterica }^{a} \\
\text { sHR }(95 \% \mathrm{Cl})\end{array}$ \\
\hline \multicolumn{5}{|l|}{ Age at diagnosis, y } \\
\hline$<50$ & Ref & Ref & Ref & Ref \\
\hline $50-59$ & $1.97(1.40-2.98)$ & $1.90(0.75-4.80)$ & $0.47(0.16-1.40)$ & $2.58(1.42-4.70)$ \\
\hline $60-69$ & $3.63(2.48-5.31)$ & $3.69(1.60-8.49)$ & $1.50(0.66-3.41)$ & $4.57(2.60-8.05)$ \\
\hline$\geq 70$ & $8.38(5.83-12.0)$ & $4.39(1.94-9.94)$ & $2.04(0.96-4.31)$ & $13.39(7.76-23.1)$ \\
\hline \multicolumn{5}{|l|}{ Sex } \\
\hline Female & $0.73(0.62-0.87)$ & $0.48(0.33-0.71)$ & $0.52(0.28-0.95)$ & $0.94(0.76-1.16)$ \\
\hline Male & Ref & Ref & Ref & Ref \\
\hline \multicolumn{5}{|l|}{ Comorbidity burden } \\
\hline Low (ADG 0-9) & Ref & Ref & Ref & Ref \\
\hline High (ADG $\geq 10$ ) & $1.73(1.46-2.04)$ & $1.29(0.87-1.92)$ & $2.68(1.47-4.89)$ & $1.66(1.34-2.07)$ \\
\hline \multicolumn{5}{|l|}{ Deprivation quintile } \\
\hline 1st (least deprived) & Ref & Ref & Ref & Ref \\
\hline 2nd & $0.99(0.75-1.31)$ & $1.19(0.59-2.40)$ & $1.30(0.46-3.63)$ & $0.92(0.64-1.31)$ \\
\hline $3 r d$ & $1.18(0.90-1.56)$ & $1.32(0.66-2.64)$ & $1.85(0.65-5.26)$ & $0.95(0.67-1.37)$ \\
\hline 4 th & $1.34(1.03-1.76)$ & $1.97(1.03-3.74)$ & $0.71(0.20-2.50)$ & $1.19(0.85-1.67)$ \\
\hline 5th (most deprived) & $1.68(1.30--2.16)$ & $1.84(0.98-3.47)$ & $3.94(1.57-9.89)$ & $1.54(1.12-2.12)$ \\
\hline \multicolumn{5}{|l|}{ Location of residence } \\
\hline Rural & $1.16(0.90-1.50)$ & $0.77(0.38-1.56)$ & $0.71(0.17-2.94)$ & $1.35(0.98-1.85)$ \\
\hline Urban & Ref & Ref & Ref & Ref \\
\hline \multicolumn{5}{|l|}{ Year of diagnosis } \\
\hline $2001-2008$ & Ref & Ref & Ref & Ref \\
\hline 2009-2015 & $0.85(0.72-0.99)$ & $0.94(0.65-1.38)$ & $1.39(0.74-2.61)$ & $0.80(0.65-1.00)$ \\
\hline \multicolumn{5}{|l|}{ Primary NET site } \\
\hline Bronchopulmonary & Ref & - & - & - \\
\hline Gastroenteric & $1.81(0.45-2.28)$ & - & - & - \\
\hline Pancreatic & $1.31(0.93-1.85)$ & - & - & - \\
\hline Others & $1.38(1.02-1.86)$ & - & - & - \\
\hline Gastric & - & - & - & $1.89(1.27-2.81)$ \\
\hline Small intestinal & - & - & - & $2.15(1.54-3.00)$ \\
\hline Colonic & - & - & - & $1.64(1.14-2.36)$ \\
\hline Rectal & - & - & - & Ref \\
\hline \multicolumn{5}{|l|}{ Metastatic status } \\
\hline None & Ref & Ref & Ref & Ref \\
\hline Synchronous ${ }^{b}$ & $0.64(0.53-0.77)$ & $0.52(0.33-0.82)$ & $1.08(0.53-2.22)$ & $0.50(0.39-0.65)$ \\
\hline Metachronous $^{c}$ & $0.68(0.52-0.89)$ & $0.26(0.10-0.72)$ & $2.72(1.34-5.54)$ & $0.56(0.38-0.81)$ \\
\hline
\end{tabular}

Abbreviations: ADG, aggregated diagnosis group; NET, neuroendocrine tumor; $\mathrm{sHR}$, subhazard ratio.

aGastroenteric: stomach, small intestine, colon, rectum.

bynchronous: $<6$ months from diagnosis.

cMetachronous: $\geq 6$ months from diagnosis. 